\title{
Erratum to: Efficient force prediction for incremental sheet forming and experimental validation
}

\author{
Yanle Li • Zhaobing Liu • Haibo Lu •
}

W. J. T. (Bill) Daniel • Sheng Liu • Paul A. Meehan

Published online: 9 May 2014

(C) Springer-Verlag London 2014

\section{Erratum to: Int J Adv Manuf Technol}

DOI: 10.1007/s00170-014-5665-2

The first sentence in section 3 needs to be changed into:

In this model, the energy method [19] and upper bound theory [17] are used to analyse the deformation behaviour and predict the tangential force of the truncated cone during the ISF process.

The division of deformation zone in Figures 5 and 16 referred to Figure 2 in [17].

\section{References}

17. Mirnia MJ, Dariani BM (2012) Analysis of incremental sheet metal forming using the upper-bound approach. Proceedings of the Institution of Mechanical Engineers, Part B: Journal of Engineering Manufacture

19. Halmos GT (2006) Roll forming handbook, vol 67, Book, Whole. CRC/Taylor \& Francis, Boca Raton

The online version of the original article can be found at doi:10.1007/ s00170-014-5665-2.

Y. Li $(\varangle) \cdot$ Z. Liu $\cdot$ H. Lu $\cdot$ W. J. T. (B). Daniel $\cdot$ S. Liu $\cdot$ P. A. Meehan School of Mechanical and Mining Engineering, The University of Queensland, St Lucia, Brisbane, QLD 4072, Australia

e-mail: yanle.li@uq.edu.au 